\title{
Relationships Between Glycemic Control and Platelet Indices, Atherogenic Index of Plasma and Vitamin D in Patients with Type 2 Diabetes
}

\author{
๑ Gökhan Çakırca1, ๑ Muhammet Murat Çelik²
}

${ }^{1}$ Mehmet Akif İnan Training and Research Hospital, Clinic of Biochemistry, Şanlıurfa, Turkey

${ }^{2}$ Mustafa Kemal University, Faculty of Medicine, Department of Internal Medicine, Hatay, Turkey

\begin{abstract}
Objectives: Vitamin D deficiency, increased platelet indices and abnormal lipid profile are closely associated with increased vascular complications in type 2 diabetes mellitus (T2DM) patients. We investigated the relationship between glycemic control and platelet indices, vitamin $\mathrm{D}$, atherogenic index of plasma (AIP) and other lipid components in T2DM patients.

Materials and Methods: Diabetic subjects were divided into the groups 1 (good glycemic control, $\mathrm{n}=59$ patients), 2 (moderate glycemic control, $\mathrm{n}=71$ patients), and 3 (poor glycemic control, $\mathrm{n}=95$ patients) according to the $\mathrm{HbA} 1 \mathrm{c}$ levels of $<7 \%, 7-9 \%$, and $>9 \%$, respectively. We retrospectively analyzed serum lipid profile, platelet count, platelet indices, calcium, phosphorus, vitamin D and $\mathrm{HbA1c}$ levels in all patients. The AIP values of the subjects were calculated as follows: $\mathrm{AIP}=[\log$ triglyceride/high density lipoprotein cholesterol (HDLc)].
\end{abstract}

Results: In group 1, the mean platelet volume (MPV), platelet distribution width (PDW), platelet large cell ratio (P-LCR), triglyceride and AIP levels were lower, and the HDLc levels were higher than in group 3. Platelet indices, lipid profile, and AIP values of group 2 did not differ from those of group 1 or group 3. There was no difference among the three groups in terms of vitamin D levels. HBA1c levels were positively correlated with the duration of diabetes, triglycerides, AIP, PDW, MPV, and P-LCR, and negatively correlated with HDLc.

Results: Increased platelet indices (MPV, PDW and P-LCR) and AIP values were observed in poor glycemic controlled diabetics. Accordingly, these parameters may be helpful in assessing increased cardiovascular risk in diabetics.

Keywords: Glycemic control, platelet indices, vitamin D, atherogenic index of plasma.

Address for Correspondence: Gökhan Çakırca, Mehmet Akif İnan Training and Research Hospital, Clinic of Biochemistry,

Şanlıurfa, Turkey

e-mail: cakirca.gokhan@gmail.com ORCID: orcid.org/0000-0003-1526-5899

Received: 18.08.2019 Accepted: 02.09.2019

Cite this article as: Çakırca G, Çelik MM. Relationships Between Glycemic Control and Platelet Indices, Atherogenic Index of

Plasma and Vitamin D in Patients with Type 2 Diabetes.

EJCM 2019;7(3):147-152.

DOI: 10.32596/ejcm.galenos.2019.08.047

${ }^{\circ}$ Copyright 2019 by Heart and Health Foundation of Turkey (TÜSAV) / E Journal of Cardiovascular Medicine published by Galenos Publishing House. 


\section{Introduction}

Cardiovascular diseases (CVDs) are a serious complication of type 2 diabetes mellitus (T2DM) and the primary cause of death and disability in diabetics ${ }^{(1)}$. Abnormal metabolic conditions (such as chronic hyperglycemia, dyslipidemia and insulin resistance) accompanying diabetes may contribute to increased platelet activation and platelet hyperreactivity ${ }^{(2)}$. Platelet activation, which is known to be associated with cardiovascular risk factors that accelerate atherogenesis ${ }^{(3)}$, can easily be estimated by measuring platelet indices, mean platelet volume (MPV), platelet distribution width (PDW), plateletcrit (PCT), and platelet large cell ratio (P-LCR) in automatic complete blood count profiles ${ }^{(4)}$. MPV, PCT, and PDW levels are reported to be higher in diabetic patients compared to healthy controls ${ }^{(5)}$.

Changes in lipid profiles (increased triglycerides and low-density lipoprotein cholesterol (LDLc) levels and decreased high-density lipoprotein cholesterol (HDLc) levels) are associated with increased cardiovascular event rates in diabetic patients ${ }^{(6)}$. Increasing evidence indicates that atherogenic index of plasma (AIP), which is defined as $\log$ (triglycerides/HDLc), is superior to other lipid parameters in predicting CVD risk $^{(7,8)}$. It has also been reported that AIP can be used to evaluate the risk of $\mathrm{T}^{2} \mathrm{DM}^{(9)}$.

The function of vitamin D is not limited to the maintenance of mineral homeostasis and skeletal health but also includes physiological functions in extraskeletal tissues ${ }^{(10)}$. Substantial evidence suggests that vitamin $\mathrm{D}$ affects the mechanisms associated with the pathophysiology of T2DM, including pancreatic beta cell function, insulin action, and secretion ${ }^{(11,12)}$. Additionally, vitamin D deficiency may increase the risk of cardiovascular disease in diabetics ${ }^{(13,14)}$.

Accumulating evidence has shown a close association between poor glycemic control and the development and progression of diabetes-related complications such as CVD, nephropathy and retinopathy ${ }^{(15,16)}$. Platelet indices, vitamin D, AIP, and other lipid parameters have been evaluated separately in T2DM patients. Here, we examined the relationship between glycemic control and levels of these parameters in patients with T2DM.

\section{Materials and Methods}

This retrospective study was conducted between January 2015 and March 2016 at the Department of Internal Medicine of Mustafa Kemal University Hospital in Hatay Province, Turkey. A total of 225 diabetic subjects were divided into three groups according to their hemoglobin A1c (HbAlc) levels. There were 59 patients with $\mathrm{HbA1c}<7 \%$ (group 1), 71 patients with $\mathrm{HbA1c} 7-9$ $\%$ (group 2), and 95 patients with $\mathrm{HbAlc}>9 \%$ (group $3)$. Group 1, group 2 and group 3 were defined as having good, moderate and poor glycemic control, respectively ${ }^{(17)}$. Vitamin D (25-hydroxyvitamin D) level of less than 20 $\mathrm{ng} / \mathrm{mL}$ was considered as hypovitaminosis $\mathrm{D}^{(12)}$. Patients with hematological diseases, active inflammation, infection, liver problems, end stage renal failure and other endocrinology disorders (other than T2DM), pregnancy and malignancy were excluded from the study. None of the patients used anticoagulant medications, vitamin D supplements or lipid-lowering drugs.

Demographic characteristics and laboratory results including lipids, complete blood count, calcium, phosphorus, vitamin $\mathrm{D}$ and $\mathrm{HbA} 1 \mathrm{c}$ levels of the subjects were obtained from hospital records. Complete blood count analyses were carried out in tubes containing K2 ethylenediamine tetraacetic acid (EDTA) on a Sysmex XN1000 instrument (Sysmex Corp., Kobe Japan) within 2 hours. Serum lipid parameters (total cholesterol, HDLc, LDLc, and triglyceride), calcium and phosphorus levels were run by standard methods on the ARCHITECTc 8000 (Abbot, Lake Forest, Illinois, USA). Vitamin D levels were analyzed on an ADVIA Centaur XP Immunoassay System (Siemens, Munich, Germany). HbA1c values of patients were measured by ion-exchange chromatography in a Bio-Rad Variant II system (Bio-Rad, Hercules, CA, USA). Daily quality control was carried out with commercial quality control materials to ensure the 
precision and accuracy of measurements in our laboratory. The AIP values of patients with T2DM were calculated as follows: $\mathrm{AIP}=(\log \text { triglyceride/HDLc })^{(18)}$.

\section{Statistical Analysis}

Statistical analyses were performed by using SPSS (Version 20, Chicago IL, USA). The normality test of variables was evaluated by using the Kolmogorov-Smirnov test. Differences among the groups in terms of gender distribution were determined using the chi-square test. ANOVA and post-hoc Tukey tests were used to compare normally distributed variables. When the variables were not normally distributed, Kruskal-Wallis test was utilized and pairwise comparisons were performed by using MannWhitney U test with Bonferroni correction. Correlations were determined using Spearman and Pearson correlation tests. Significance was accepted at $p<0.05(p<0.0167$ for Mann-Whitney U test with Bonferroni correction).

\section{Results}

Demographic and laboratory data of the study groups are provided in Table 1. There were no differences among the three groups according to age, gender distribution, and diabetes duration.

LDLc and total cholesterol levels were similar among the three groups. The triglyceride and AIP values were significantly higher and the HDLc levels were significantly lower in group 3 than in group 1. The triglyceride, HDLc, AIP values of group 2 did not differ from group 1 or group 3.

Platelet count and PCT values were similar in all groups. MPV, PDW, and P-LCR levels were significantly higher in group 3 than in group 1. MPV, PDW and P-LCR levels of group 2 did not differ from those of group 1 or group 3.

The prevalence of hypovitaminosis D was $85.3 \%$ $(\mathrm{n}=192)$, and that of vitamin D sufficiency was $14.7 \%$ $(n=33)$ in patients with T2DM. There were no differences in vitamin $\mathrm{D}$, calcium, and phosphorus levels among groups.
The correlations between HBA1c and other parameters (age, lipid profile, atherogenic index, platelet indices, calcium, phosphorus and vitamin D) are presented in table 2. The levels of HBA1c were positively correlated with the duration of the diabetes, triglycerides, AIP, PDW, MPV and P-LCR, and inversely with HDLc. In addition, vitamin $\mathrm{D}$ level was inversely correlated with triglycerides $(\mathrm{r}=-0.224, \mathrm{p}=0.001)$ and AIP $(\mathrm{r}=-0.202, \mathrm{p}=0.004)$. There was no correlation between platelet indices and AIP and vitamin D levels $(\mathrm{p}>0.05)$.

\section{Discussion}

Accumulating research suggests that dyslipidemia ${ }^{(6)}$, vitamin D deficiency ${ }^{(13,14)}$ and increased platelet indices $^{(19,20)}$ are closely associated with increased cardiovascular events in diabetic populations. Platelet activation is increased in diabetic subjects due to factors such as hyperglycemia, hyperinsulinemia, and atherogenic dyslipidemia ${ }^{(21)}$. Platelet activation contributes to the increased risk of atherothrombotic events in these patients ${ }^{(2)}$ and can easily be estimated by measuring platelet indices ${ }^{(4)}$.

Many studies have shown that MPV, PCT, PDW, and P-LCR levels are higher in diabetics than in non-diabetic individuals $^{(22-24)}$. Several authors have also suggested that increased MPV and PDW are associated with the presence of diabetes-related complications in T2DM patients ${ }^{(24-26)}$. On the other hand, it has been observed that platelet indices tend to decrease in patients with good glycemic control $^{(5,27,28)}$. Similarly, we determined that MPV, PDW, and P-LCR levels were lower in T2DM patients with good glycemic control compared to the poor glycemic control group, and a positive correlation was observed between HbA1c and these parameters. These results suggest that poor glycemic control contributes to increased platelet activation, thereby increasing cardiovascular events in diabetics.

Patients with T2DM tend to have abnormal lipid profiles that increase cardiovascular event rates ${ }^{(29)}$. AIP, a newly developed lipid index, is closely associated with 
the risk of $\mathrm{T}_{2} \mathrm{DM}^{(9)}$. Furthermore, high AIP is closely associated with an increased risk of microvascular complications in diabetics ${ }^{(30)}$. On the other hand, Kocak et al. ${ }^{(31)}$ found that serum cholesterol, LDLc, and TG levels were higher, and HDLc levels were lower, in unregulated diabetic patients $(\mathrm{HbA} 1 \mathrm{c} \geq 7 \%)$ compared to regulated diabetics $(\mathrm{HbA} 1 \mathrm{c}<7 \%)$. Another study has emphasized that HbA1c is a good indicator of lipid profile ${ }^{(32)}$. In the present study, high AIP and triglyceride levels and low HDL levels were observed in the unregulated group ( $\mathrm{HbA} 1 \mathrm{c}>9 \%$ ) compared to the regulated group (HbA1c $<7 \%$ ). HBA1c levels were positively correlated with triglycerides and AIP, and inversely correlated with HDLc. Collectively, these results showed that in diabetics, lipid

Table 1. Characteristics and laboratory data of study groups

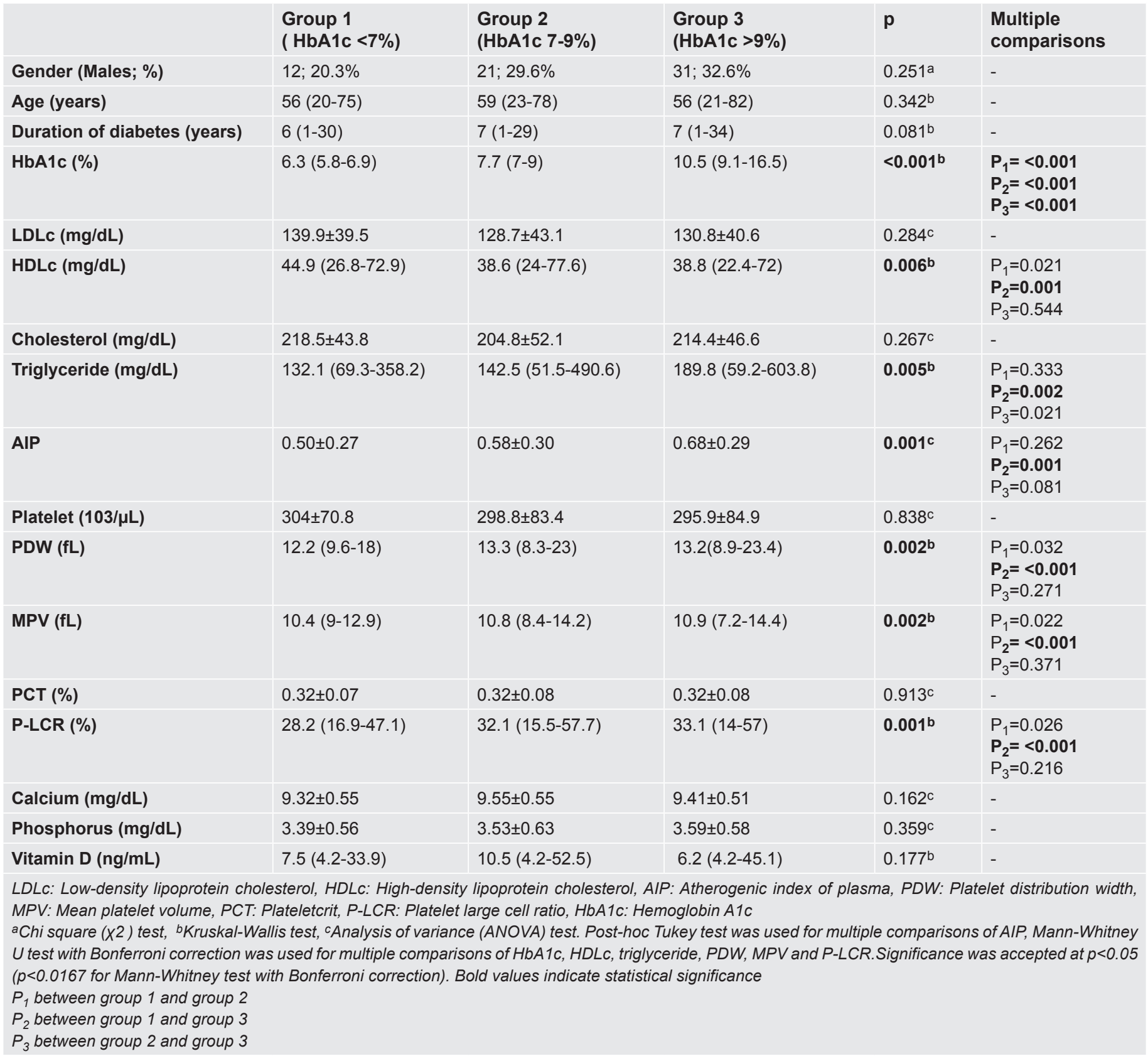


Table 2. Correlation between HBA1c levels and other variables in diabetic patients

\begin{tabular}{|c|c|c|}
\hline & \multicolumn{2}{|l|}{ HBA1c } \\
\hline & $\mathbf{r}$ & $\mathbf{p}$ \\
\hline Age & 0.052 & 0.437 \\
\hline Duration of diabetes & 0.160 & $0.016^{*}$ \\
\hline LDLc & -0.043 & 0.537 \\
\hline HDLc & -0.191 & $0.006^{*}$ \\
\hline Cholesterol & 0.038 & 0.591 \\
\hline Triglyceride & 0.274 & $<0.001^{*}$ \\
\hline AIP & 0.290 & $<0.001^{*}$ \\
\hline Platelet & -0.036 & 0.596 \\
\hline PDW & 0.216 & $0.001^{*}$ \\
\hline MPV & 0.221 & $0.001^{*}$ \\
\hline РCT & 0.011 & 0.872 \\
\hline P-LCR & 0.240 & $<0.001^{*}$ \\
\hline Calcium & 0.017 & 0.842 \\
\hline Phosphorus & 0.167 & 0.057 \\
\hline Vitamin D & -0.117 & 0.079 \\
\hline \multicolumn{3}{|c|}{$\begin{array}{l}\text { LDLc: Low-density lipoprotein cholesterol, HDLc: High-density lipoprotein } \\
\text { cholesterol, AIP: Atherogenic index of plasma, PDW: Platelet distribution } \\
\text { width, MPV: Mean platelet volume, PCT: Plateletcrit, P-LCR: Platelet large } \\
\text { cell ratio, HbA1c: Hemoglobin A1c } \\
{ }^{*} p<0.05\end{array}$} \\
\hline
\end{tabular}

profile and blood glucose should be controlled to prevent or slow the progression of diabetic complications.

Low vitamin D levels have been shown to be associated with decreased insulin sensitivity and increased risk of developing $\mathrm{T}^{2} \mathrm{DM}^{(33,34)}$. For example, Chiu et al. ${ }^{(12)}$ found that vitamin D levels were positively correlated with insulin sensitivity and inversely with glucose. Another study examined the relationship between vitamin D and HBA1c in diabetic patients between November 2016 and June 2017. They found that vitamin D levels were higher in the well-controlled group ( $\mathrm{HbAlc}<8 \%$ ) than in the poorly controlled group $(\mathrm{HbA} 1 \mathrm{c} \geq 8 \%)^{(35)}$. In contrast, we did not identify differences in vitamin $\mathrm{D}$ levels between diabetic groups. This discrepancy may be attributed to the fact that seasonal changes in vitamin $\mathrm{D}$ determinations were ignored, and that vitamin D deficiency was present in $85.3 \%$ of our diabetic patients. We also found a negative correlation between vitamin $\mathrm{D}$ level and triglycerides and
AIP. Consistent with our own findings, an observational study showed that vitamin D was inversely related to total cholesterol/HDLc or LDLc/HDLc ratios and triglyceride levels, and that high vitamin $\mathrm{D}$ concentrations were related to a favorable lipid panel ${ }^{(36)}$.

The main limitation of this study is that it was a singlecenter retrospective study. Consequently, we found an association between improved glycemic control in T2DM and decreased MPV, PDW, P-LCR, triglycerides and AIP levels and increased HDLc. Future studies should be conducted to confirm these findings.

\section{Ethics}

Ethics Committee Approval: Ethical approval for this study was obtained from the Mustafa Kemal University Ethics Committee (Protocol code: 09/05/2016/100).

Informed Consent: Since the study was a retrospective study, informed consent was not obtained.

Peer-review: Externally and internally peer-reviewed.

\section{Authorship Contributions}

Surgical and Medical Practices: M.M.Ç., Concept: G.Ç., M.M.Ç., Design: G.Ç., M.M.Ç., Data Collection or Processing: G.Ç., M.M.Ç., Analysis or Interpretation: G.Ç., M.M.Ç., Literature Search: G.Ç., Writing: G.Ç., M.M.Ç.

Conflict of Interest: No conflict of interest was declared by the authors.

Financial Disclosure: The authors declared that this study received no financial support.

\section{References}

1. Morrish NJ, Wang SL, Stevens LK, Fuller JH, Keen H. Mortality and causes of death in the WHO Multinational Study of Vascular Disease in Diabetes. Diabetologia 2001;44:14-21.

2. Ferroni P, Basili S, Falco A, Davì G. Platelet activation in type 2 diabetes mellitus. J Thromb Haemost 2004;2:1282-91.

3. Davi G, Patrono C. Platelet activation and atherothrombosis. N Engl J Med 2007;357:2482-94

4. Çakırca G, Çelik MM. Lipid profile and atherogenic indices and their association with platelet indices in familial Mediterranean fever. Turk Kardiyol Dern Ars 2018;46:184-90. 
5. Demirtas L, Degirmenci H, Akbas EM, et al. Association of hematological indicies with diabetes, impaired glucose regulation and microvascular complications of diabetes. Int J Clin Exp Med 2015;8:11420-7.

6. Martín-Timón I, Sevillano-Collantes C, Segura-Galindo A, del CañizoGómez FJ. Type 2 diabetes and cardiovascular disease: have all risk factors the same strength? World J Diabetes 2014;5:444-70.

7. Cai G, Shi G, Xue S, Lu W. The atherogenic index of plasma is a strong and independent predictor for coronary artery disease in the Chinese Han population. Medicine (Baltimore) 2017; 96:e8058.

8. Zhu L, Lu Z, Zhu L, et al. Lipoprotein ratios are better than conventional lipid parameters in predicting coronary heart disease in Chinese Han people. Kardiol Pol 2015;73:931-8.

9. Zhu XW, Deng FY, Lei SF. Meta-analysis of atherogenic index of plasma and other lipid parameters in relation to risk of type 2 diabetes mellitus. Prim Care Diabetes 2015;9:60-7.

10. Reid IR, Bolland MJ. Skeletal and nonskeletal effects of vitamin D: is vitamin D a tonic for bone and other tissues? Osteoporos Int 2014;25:234757.

11. Zeitz U, Weber K, Soegiarto DW, Wolf E, Balling R, Erben RG. Impaired insulin secretory capacity in mice lacking a functional vitamin $\mathrm{D}$ receptor. FASEB J 2003;17:509-11.

12. Chiu KC, Chu A, Go VLW, Saad MF. Hypovitaminosis D is associated with insulin resistance and $\beta$ cell dysfunction. Am J Clin Nutr 2004;79:820-5.

13. Cigolini M, Iagulli MP, Miconi V, Galiotto M, Lombardi S, Targher G. Serum 25-hydroxyvitamin D3 concentrations and prevalence of cardiovascular disease among type 2 diabetic patients. Diabetes Care 2006;29:722-4.

14. Targher G, Bertolini L, Padovani R, et al. Serum 25-hydroxyvitamin D3 concentrations and carotid artery intima-media thickness among type 2 diabetic patients. Clin Endocrinol (Oxf) 2006;65:593-7.

15. Ceriello A, Ihnat MA, Thorpe JE. Clinical review 2: The "metabolic memory": is more than just tight glucose control necessary to prevent diabetic complications? J Clin Endocrinol Metab 2009;94:410-5.

16. Fasil A, Biadgo B, Abebe M. Glycemic control and diabetes complications among diabetes mellitus patients attending at University of Gondar Hospital, Northwest Ethiopia. Diabetes, Metab Syndr Obes 2019;12:75-83.

17. Chiang CY, Lee JJ, Chien ST, et al. Glycemic control and radiographic manifestations of tuberculosis in diabetic patients. PLoS One 2014;9:e93397.

18. Dobiásová M, Frohlich J. The plasma parameter log (TG/HDL-C) as an atherogenic index: correlation with lipoprotein particle size and esterification rate in apoB-lipoprotein-depleted plasma (FER(HDL)). Clin Biochem 2001;34:583-8.

19. Sahin DY, Gür M, Elbasan Z, et al. Mean platelet volume and extent and complexity of coronary artery disease in diabetic and nondiabetic patients with ST elevation myocardial infarction. Angiology 2013;64:505-11.

20. Tavil Y, Sen N, Yazici H, et al. Coronary heart disease is associated with mean platelet volume in type 2 diabetic patients. Platelets 2010;21:368-72.
21. Ferreiro JL, Gómez-Hospital JA, Angiolillo DJ. Platelet abnormalities in diabetes mellitus. Diab Vasc Dis Res 2010;7:251-9.

22. Shilpi K, Potekar RM. A study of platelet indices in type 2 diabetes mellitus patients. Indian J Hematol Blood Transfus 2018;34:115-20.

23. Alhadas K, Santos SN, Freitas MMS, Viana SMSA, Ribeiro LC, Costa MB. Are platelet indices useful in the evaluation of type 2 diabetic patients? J Bras Patol Med Lab 2016;52:96-102.

24. Jindal S, Gupta S, Gupta R, et al. Platelet indices in diabetes mellitus: indicators of diabetic microvascular complications. Hematology 2011;16:86-9.

25. Xiao W, Huang Y, Dong J, Zhang X, Hu J. Relationship between platelet volume indices with macrovascular and peripheral neuropathy complications in type 2 diabetic patients. J Diabetes 2014;6:298-303.

26. Papanas N, Symeonidis G, Maltezos E, et al. Mean platelet volume in patients with type 2 diabetes mellitus. Platelets 2004;15:5-9.

27. Ulutas KT, Dokuyucu R, Sefil F, et al. Evaluation of mean platelet volume in patients with type 2 diabetes mellitus and blood glucose regulation: a marker for atherosclerosis? Int J Clin Exp Med 2014;7:955-61.

28. Demirtunc R, Duman D, Basar M, Bilgi M, Teomete M, Garip T. The relationship between glycemic control and platelet activity in type 2 diabetes mellitus. J Diabetes Complications 2009;23:89-94.

29. Nayak BS, Butcher DM, Bujhawan S, et al. Association of low serum creatine, abnormal lipid profile, gender, age and ethnicity with type 2 diabetes mellitus in Trinidad and Tobago. Diabetes Res Clin Pract 2011;91:342-7.

30. Zoppini G, Negri C, Stoico V, Casati S, Pichiri I, Bonora E. Triglyceridehigh density lipoprotein cholesterol is associated with microvascular complications in type 2 diabetes mellitus. Metabolism 2012;61:22-9.

31. Kocak MZ, Aktas G, Erkus E, Sincer I, Atak B, Duman T. Serum uric acid to HDL-cholesterol ratio is a strong predictor of metabolic syndrome in type 2 diabetes mellitus. Rev Assoc Med Bras 2019;65:9-15.

32. Khan HA, Sobki SH, Khan SA. Association between glycaemic control and serum lipids profile in type 2 diabetic patients: HbAlc predicts dyslipidaemia. Clin Exp Med 2007;7:24-9.

33. Ford ES, Ajani UA, McGuire LC, Liu S. Concentrations of serum vitamin D and the metabolic syndrome among U.S. adults. Diabetes Care 2005;28:1228-30.

34. Scragg R, Sowers M, Bell C. Serum 25-hydroxyvitamin D, diabetes, and ethnicity in the Third National Health and Nutrition Examination Survey. Diabetes Care 2004;27:2813-8.

35. Erkus E, Aktas G, Kocak MZ, Duman TT, Atak BM, Savli H. Diabetic regulation of subjects with type 2 diabetes mellitus is associated with serum vitamin D levels. Rev Assoc Med Bras 2019;65:51-5.

36. Jorde R, Grimnes G. Vitamin D and metabolic health with special reference to the effect of vitamin D on serum lipids. Prog Lipid Res 2011;50:303-12. 